\title{
RELAÇÃO SOLO/VEGETAÇÃO EM AMBIENTE DE CERRADO SOBRE INFLUÊNCIA DO GRUPO URUCUIA ${ }^{1}$
}

\author{
SOIL-VEGETATION RELATION IN CERRADO ENVIROMENT UNDER INFLUENCE OF THE \\ GROUP URUCUIA
}

\author{
Renata Botelho Machado da Silva ${ }^{2}$ Márcio Rocha Francelino ${ }^{3}$ Pedro Adnet Moura ${ }^{4}$ \\ Tom Adnet Moura ${ }^{4}$ Marcos Gervasio Pereira ${ }^{5}$ Camila Paula de Oliveira ${ }^{6}$
}

\begin{abstract}
RESUMO
A vegetação de Cerrado brasileiro compreende um mosaico natural de fisionomias, de campos abertos a savanas e florestas. Acredita-se que a presença de diferentes fitofisionomias em uma região pode ser explicada em parte pela relação direta com os atributos do solo presentes na mesma. O presente trabalho objetivou estudar a relação entre solo e vegetação em uma área do Bioma Cerrado sobre influência do Grupo Urucuia. Para tanto, foi realizado um levantamento de solos e vegetação na escala 1:50.000 em uma área de aproximadamente 32 mil hectares localizada na região da tríplice divisa entre Minas Gerais, Goiás e Bahia, tendo como substrato o arenito do Grupo Urucuia. Os resultados analíticos das classes de solos foram relacionados com os dados das fitofisionomias presentes através de análise estatística comum e pela determinação dos componentes principais. Os solos da região refletiram bem o material de origem, apresentando elevados teores de areia, com predomínio de Latossolo Vermelho Amarelo distrófico típico e Latossolo Amarelo Distrófico psamítico, presentes em mais de 35\% de toda a área de estudo. A fitofisionomia mais comum foi o Cerrado sentido restrito típico. A análise dos componentes principais indicou que a areia fina, a argila e o alumínio responderam por $93,7 \%$ da variabilidade da relação entre solos e as fitofisionomia. Palavras-chave: geoprocessamento; análise canônica; levantamento de solos.
\end{abstract}

\section{ABSTRACT}

The Brazilian Cerrado vegetation comprises a mosaic of natural types, from open fields to savannas and forests. It is believed that the presence of different vegetation types in a region can be explained in part by the direct relationship with the attributes present in the same soil. The present study investigated the relationship between soil and vegetation in an area of Cerrado biome with influence of Urucuia Group. To do so, we conducted a survey of soils and vegetation in 1:50,000 scale in an area of approximately 32,000 hectares located in the tri-border region of Minas Gerais, Goiás and Bahia states, with the sandstone substrate of Urucuia Group. The analytical results of soil classes were related to the present data of the physiognomies through common statistical analysis and through the determination of the main components. The soils of the region reflected well the source material, with high percentages of sand, with a predominance of Oxisol

1 Parte da dissertação de mestrado do primeiro autor apresentada ao Programa de Pós-graduação em Ciências Ambientais e Florestais da Universidade Federal Rural do Rio de Janeiro, Brasil.

2 Engenheira Florestal, Mestre, Rua Major Rubens Vaz, 226, Gávea, CEP 22470-070, Rio de Janeiro (RJ), Brasil. renata.machado@trijuncao.com.br

3 Engenheiro Agrônomo, Dr., Professor Associado do Departamento de Solos, Universidade Federal de Viçosa, Av. PH Rolfs, s/n, CEP 36570-000, Viçosa (MG), Brasil. marcio.francelino@ufv.br

4 Engenheiro Florestal, Empresa Adnet Florestal, Rua Jorge José Pedro, 1, Lumiar, CEP 28616-095, Nova Friburgo (RJ), Brasil.

5 Engenheiro Agrônomo, Dr., Professor Associado, Departamento de Solos, Universidade Federal Rural do Rio de Janeiro, BR $465 \mathrm{~km} \mathrm{07,} \mathrm{CEP} \mathrm{23890-000,} \mathrm{Seropédica} \mathrm{(RJ),} \mathrm{Brasil.}$

6 Engenheira Florestal, mestranda do Programa de Pós-graduação em Ciências Ambientais e Florestais, Universidade Federal Rural do Rio de Janeiro, BR 465 km 07, CEP 23890-000, Seropédica (RJ), Brasil.

Recebido para publicação em 16/11/2012 e aceito em 3/09/2013 
Hapludox and Oxisol dystrophic, present in over $35 \%$ of the entire study area. The most common vegetation type was Cerrado sense, restrict and typical. The principal component analysis indicated that the fine sand, clay and aluminum accounted for $93.7 \%$ of the variability of the relationship between soils and vegetation type

Keywords: GIS; canonical analysis, survey of soils.

\section{INTRODUÇÃO}

Dentre os fatores que interferem na formação e compreensão da paisagem, o solo desempenha papel fundamental, fornecendo suporte mecânico e disponibilizando os nutrientes essenciais para a instalação e desenvolvimento dos vegetais. O solo também possui relações, diretas ou indiretas, com as diferentes fitofisionomias de uma região que, no entanto, segundo Rossi et al. (2005), são pouco estudadas. Conhecer a vegetação natural e sua relação com os solos em que ocorrem, além de auxiliar no entendimento da biodiversidade, pode contribuir para orientar os projetos de restauração da vegetação (KOTCHETKOFF-HENRIQUES et al., 2005) e determinar áreas passíveis de atividades agrossilvipastoris, de forma a causar o menor impacto possível no ecossistema local.

Nas últimas décadas, o Cerrado se tornou uma região estratégica para o agronegócio, o que levou a instalação de um processo sistemático de desmatamento, em que parte da sua vegetação original foi substituída por monoculturas exóticas. Apesar de ser uma importante fronteira agrícola para o país, colaborando com o favorecimento da balança comercial e produzindo commodities agrícolas fundamentais para o desenvolvimento da economia, essa expansão tem sido feita de forma indiscriminada, sem levar em conta importantes áreas de alto valor ambiental. Sendo assim, antes de qualquer intervenção de cunho econômico na região deve-se considerar a variabilidade da paisagem e suas respectivas capacidades de suporte, tendo o solo como principal delimitador desses ambientes, de maneira a evitar uma visão simplista e imediatista e não mais incorporar ao processo produtivo, de maneira equivocada, extensas áreas com pouca vocação agropecuária, causando elevado prejuízo ambiental.

A vegetação de Cerrado brasileiro compreende um gradiente natural de fisionomias, de campos abertos a savanas e florestas, dependendo das condições do solo e da disponibilidade de água no local. Entre os fatores que proporcionam os diferentes tipos de vegetações do bioma estão as condições edáficas $(\mathrm{pH}$, saturação por alumínio, fertilidade, entre outros), clima sazonal, condições hídricas, incluindo profundidades do lençol freático e dos solos, fenologia e forma de dispersão das espécies, herbivoria, além de ações antrópicas, incluindo as frequentes queimadas (CASTRO \& KAUFFMAN, 1998; MEDEIROS, 2004; MARIMON JUNIOR e HARIDASAN, 2005). Sendo assim, o Cerrado pode ser entendido como um mosaico vegetacional, já que não possui uma fisionomia única em toda a sua extensão, apresentando desde formas campestres, como os campos limpos, até formas florestais, como os cerradões. Entre estes dois extremos fisionômicos ocorrem diversas formas intermediárias de vegetação (AGNES et al., 2007).

Nesse contexto, o presente trabalho teve o objetivo de avaliar a relação existente entre o solo e duas fitofisionomias do Bioma Cerrado sobre a influência dos arenitos do Grupo Urucuia na região Centro Oeste do Brasil.

\section{MATERIAL E MÉTODOS}

O estudo foi realizado em um complexo de diversas fazendas inseridas totalmente no bioma Cerrado, nas divisas entre os estados da Bahia, Goiás e Minas Gerais, entre as coordenadas aproximadas de $14^{\circ} 42^{\prime} \mathrm{S}$ e $45^{\circ} 53^{\prime} \mathrm{O}$ (Figura 1), totalizando $32.397,64$ ha, sendo que aproximadamente $89 \%$ da área encontram-se preservados com vegetação nativa. O clima da região, de acordo com a classificação de KOPPEN, é Aw Tropical Sazonal de Inverno Seco com precipitação média mensal com grande estacionalidade e presenças de veranicos na primavera-verão. A precipitação média anual varia de $700 \mathrm{~mm}$ a $1400 \mathrm{~mm}$ (BAHIA, 1998).

A área objeto de estudo está inserida basicamentena unidadegeomorfológica denominada Chapadão Central do Domínio do Médio São Francisco, que corresponde aos relevos planos mais elevados, compreendendo a área de ocorrência do imenso chapadão que constitui o Grupo Urucuia, que se compõe de arenitos quartzosos de cores variadas, predominando castanho-avermelhados, róseos e amarelo-esbranquiçados (LIMA, 2007). 
Nos fundos dos vales são encontrados depósitos fluviais arenosos recentes.

Foi utilizado o modelo digital de elevação (MDE) do SRTM (Shuttle Radar Topography Mission) obtido gratuitamente na internet (http:// www2.jpl.nasa.gov/srtm/) reamostrado para resolução espacial de 30 metros utilizando o algoritmo topogrid do programa Arcgis 10, o qual foi utilizado na elaboração dos mapas temáticos de declividade, face de exposição e hipsometria que auxiliaram no delineamento das unidades de paisagem.

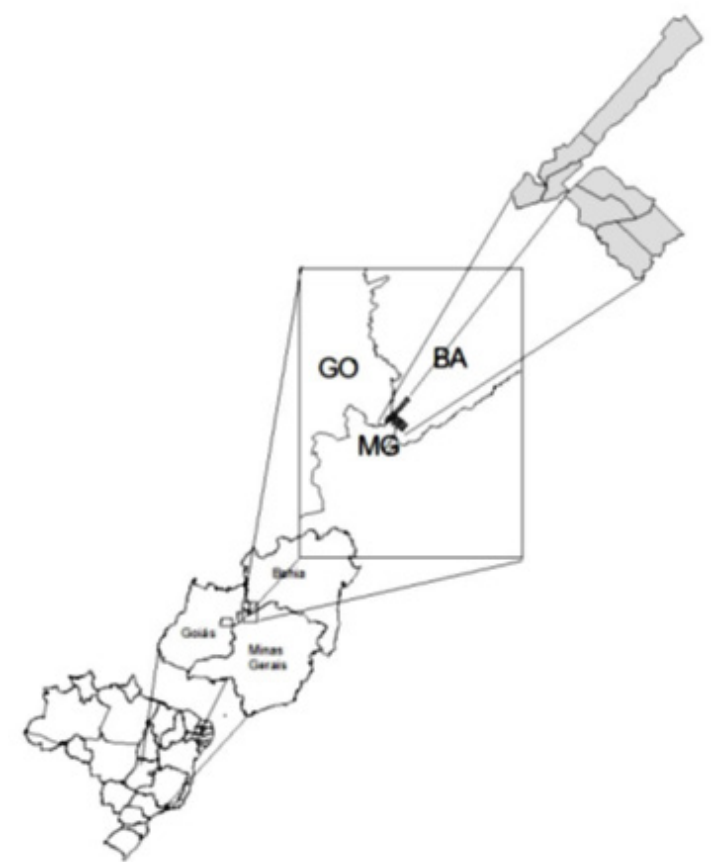

FIGURA 1: Localização da área de estudo. FIGURE 1: Location of the study area.

O mapa da vegetação foi elaborado em ambiente de Sistema de Informação Geográfica (SIG) a partir da interpretação de imagens orbitais do sensor HRC (Câmera Pancromática de Alta Resolução) do sistema CBERS-2B (Satélite SinoBrasileiro de Recursos Terrestres), com 2,7 m de resolução espacial de 16/05/2008 e do SPOT-5 com 2,5 m de resolução espacial de 30/06/2009.

Após a interpretação da imagem orbital, foram definidas unidades homogêneas que serviram de orientação para o trabalho de campo. Cada unidade previamente delimitada foi percorrida livremente por meio de caminhamento para validação do mapeamento e com auxílio de GPS de navegação, foram registradas as coordenadas das áreas onde estavam presentes as diferentes fitofisionomias e as espécies mais relevantes, conforme sugerido por Ribeiro e Walter (2008) e confirmado por observações de campo. Esses pontos foram anotados, as espécies fotografadas e quando possível coletado o material para sua identificação botânica, que foi feita através de profissionais na área utilizando literatura especializada e de comparação com as coleções dos herbários do Jardim Botânico do Rio de Janeiro e da Universidade Federal Rural do Rio de Janeiro (UFRRJ). A nomenclatura botânica baseou-se no sistema APG II (SOUZA e LORENZI, 2005) e na base de dados do Missouri Botanical Garden. O material vegetal coletado está depositado no herbário da UFRRJ.

Foi utilizada a caracterização da vegetação proposta por Ribeiro e Walter (2008) dividindo-a em formações florestais (Mata de galeria, Mata seca e Cerradão); savânicas (Cerrado sentido restrito, Parque de Cerrado, Palmeiral e Vereda) e campestres (Campo sujo, Campo limpo e Campo rupestre). Escolheu-se essa caracterização por possuir um perfil mais completo, além de melhor relação com a fitofisionomia encontrada na região. Os padrões espectrais encontrados para cada fitofisionomia presente na área de estudo foram então associados com os esquemas e caracterização proposta por Ribeiro e Walter (2008).

Para mapeamento dos solos foi realizado levantamento de reconhecimento de alta intensidade na escala de 1:50.000, visando à avaliação qualitativa e semiquantitativa dos solos. Foram realizados caminhamentos em toda a área, sendo registrados com aparelho GPS de navegação, de forma a facilitar a orientação dos transectos percorridos e posterior caracterização de solos e delineamento das unidades de mapeamento. Foram amostrados 25 perfis completos e cinco amostras extras, distribuídos ao longo de toda a área de estudo, cobrindo todas as diferentes feições de vegetação presentes. Os solos foram observados em sua maioria, em trincheiras (até 2 metros), sendo complementada a observação com tradagens. Ao todo foram coletadas 130 amostras de solos. As descrições foram realizadas conforme Manual de Descrição e Coleta de Solo no Campo (SANTOS et al., 2005) e os solos foram classificados conforme EMBRAPA (2006). As análises físicas (granulometria) e químicas $(\mathrm{pH}$, $\mathrm{H}^{+}, \mathrm{Ca}^{2+}, \mathrm{Mg}^{2+}, \mathrm{K}^{+}, \mathrm{Na}^{+}, \mathrm{P}$ e Corg) foram realizadas segundo EMBRAPA (1997), no Laboratório de Solos da UFRRJ.

As unidades de mapeamento foram identificadas por observações e amostragem ao 
longo de percursos, que cruzaram diferentes padrões de drenagem, relevo, vegetação e geomorfologia. Grande parte dos limites entre unidades de mapeamento foi estabelecida por interpretação das imagens orbital, do MDE e do mapa de declividade, com posterior verificação e ajustes no campo.

Para determinar a relação da vegetação com os resultados das análises químicas e físicas dos solos foram utilizados métodos de ordenação presentes no programa Statisitca 11, criando-se valores diferentes aos variados tipos de fitofisionomias encontrados nas Fazendas, transformando-as em variáveis quantitativas, as quais foram transformadas em números e todas normalizadas com média $0 \mathrm{e}$ variância 1. A análise multivariada foi realizada utilizando técnica canônica, envolvendo todas as variáveis em estudo, a partir da qual foi reduzido o conjunto de dados em combinações lineares. Foi gerado escores das duas primeiras variáveis canônicas que explicam mais de $80 \%$ da variação total, conforme recomendado por Cruz e Regazzi (1994).

\section{RESULTADOS E DISCUSSÃO}

Dentre as formações vegetais presente, o Cerrado sentido restrito é a fitofisionomia mais abundante na área de estudo, estendendo-se por aproximadamente $25.932,94$ ha (80\% dototal daárea) (Figura 2). Consideradas as subdivisões propostas por Ribeiro e Walter (2008), a fitofisionomia mais abundante é o Cerrado sentido restrito típico (CRT), com 21.833 ha $(67,3 \%)$, seguido pelo Cerrado sentido restrito denso (CRD) com 2.805 ha $(8,65 \%)$ e Cerrado sentido restrito ralo (CRR), com $1.294,7$ ha (3,99\%) (Tabela 1). Além das formações savânicas, somam-se os Campos Limpos (CL) e as Veredas (VE), que representam as formações campestres e ocupam um papel secundário na formação fitofisionômica da área de estudo, ocupando 5,4\% da área total. O Cerradão (CD), que representa o tipo de fitofisionomia florestal com vegetação mais adensada, é encontrado em apenas $1,5 \%$ da área. Esses resultados corroboram com Marimon Junior \& Haridasan (2005), nos quais citam que a forma mais extensa, o Cerrado sentido restrito, ocupa aproximadamente $65 \%$ da área geográfica deste bioma, enquanto que o Cerradão, apenas cerca de $1 \%$. No restante da área $(34 \%)$, diversos outros tipos fitofisionômicos e usos dividem a paisagem. A classe denominada "Outros" corresponde às áreas ocupadas por edificações e estradas.
$\mathrm{Na}$ área foram delimitadas 17 unidades de mapeamento, entre feições homogêneas e associações (Figura 3), essa última geralmente composta por duas classes (Tabela 2). A unidade mais representativa foi a associação entre Latossolo Vermelho-Amarelo Distrófico típico e Latossolo Amarelo Distrófico psamítico, que representa mais de 35\% de toda a área da Fazenda. Os Latossolos Vermelho-Amarelos são mais argilosos e são encontrados nas partes mais elevadas em encostas com declives suaves. No terço inferior, próximo do fundo de vale aplainado, ocorrem os Latossolos Amarelos, com textura mais grosseira. A separação entre essas duas classes não obedece a um padrão distinto, sendo a associação entre elas necessária. A maioria dos solos apresentou classe textural francoarenosa, com teor de argila em torno de $200 \mathrm{~g} \mathrm{~kg}^{-1}$.

Nos topos planos foram encontrados os Argissolos Vermelho-Amarelos, apresentando textura mais argilosa associada à areia fina.

\section{Relação Solo/Vegetação}

$\mathrm{Na}$ área estudada, o Cerrado sentido restrito típico foi observado principalmente sobre Latossolo Vermelho-Amarelo nos terços médio e superior, e nas partes próximas aos campos limpos, no terço inferior, sobre Neossolos Quartzarênicos. O Cerrado sentido restrito denso ocorreu principalmente sobre Latossolo Vermelho-Amarelo e Argissolos Vermelho-Amarelo nas partes mais elevadas da paisagem.

Já o Cerradão foi encontrado basicamente sobre Argissolos Vermelho-Amarelos, que apresentam teor de argila um pouco mais elevado que os demais solos. Segundo Cremon et al. (2009), a presença dessa fitofisionomia, mesmo em solos de baixa fertilidade natural, pode ter ocorrido quando em época pretérita o solo ainda podia fornecer nutrientes em quantidades maiores.

Mesmo sob uma vegetação mais densa, os solos apresentaram baixos valores de carbono orgânico, o que pode indicar uma acelerada decomposição da serrapilheira aportada, associada à lixiviação dos ácidos orgânicos de maior solubilidade oriundos do processo de decomposição, conforme observado por Loss et al. (2011). Foi também observado que o Cerradão ocorre em manchas circundadas por Cerrado sentido restrito denso e Cerrado sentido restrito típico. A transição entre essas fitofisionomias é gradual e de difícil delimitação, entretanto, a alta resolução espacial 


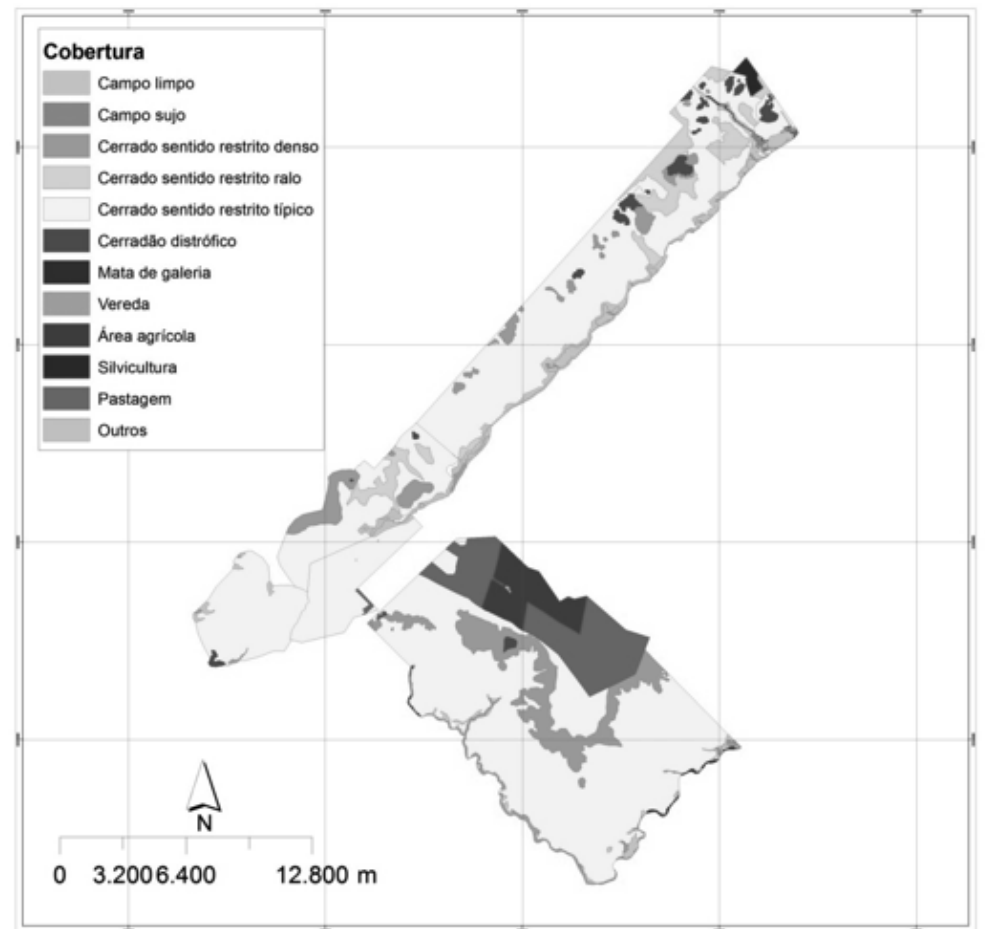

FIGURA 2: Coberturas vegetais observadas na área de estudo.

FIGURE 2: Vegetal coverage observed in the study area.

TABELA 1. Distribuição das classes de cobertura do solo.

TABLE 1. Distribution of land cover classes.

\begin{tabular}{lcc}
\hline & \multicolumn{2}{c}{ Área } \\
\hline Cobertura & Hectares & $\%$ \\
\hline Campo limpo & 1292,7 & 3,9 \\
Campo sujo & 24,6 & 0,1 \\
Cerradão distrófico & 506,0 & 1,5 \\
Cerrado sentido restrito denso & 2915,1 & 8,8 \\
Cerrado sentido restrito ralo & 1530,5 & 4,6 \\
Cerrado sentido restrito típico & 22640,7 & 68,5 \\
Mata de galeria & 80,7 & 0,2 \\
Silvicultura & 122,8 & 0,4 \\
Área agrícola & 1076,6 & 3,3 \\
Vereda & 273,1 & 0,8 \\
Lago & 27,2 & 0,1 \\
Pastagem & 2369,5 & 7,2 \\
\hline Outros & 214,2 & 0,6 \\
\hline
\end{tabular}

das imagens utilizadas permitiu uma separação satisfatória para os objetivos deste estudo. Todas as áreas apresentaram dossel contínuo com uma altura de aproximadamente $7 \mathrm{a} 11 \mathrm{~m}$ com algumas árvores podendo atingir $14 \mathrm{~m}$. A densidade de árvores estimada variou de 50 a $80 \%$ e a análise expedita da composição florística e dos solos das manchas de Cerradão indicaram que estes se enquadram nas características de Cerradão distrófico.

As Veredas ocorreram em solos 
TABELA 2: Unidades de mapeamento encontradas na área de estudo.

TABLE 2: Mapping units observed in the study area.

\begin{tabular}{|c|c|c|}
\hline \multirow[t]{2}{*}{ Classe de Solo } & \multicolumn{2}{|c|}{ Área } \\
\hline & $\mathrm{Ha}$ & $\%$ \\
\hline Argissolo Vermelho-Amarelo Distrófico arênico & 3084,1 & 9,5 \\
\hline Argissolo Vermelho-Amarelo Distrófico arênico + Latossolo Vermelho-Amarelo Distrófico típico & 3435 & 10,6 \\
\hline Gleissolo Melânico Tb Distrófico típico + Neossolo Quartzarênico Hidromórfico & 24 & 0,07 \\
\hline Gleissolo Melânico Tb Distrófico típico + Organossolo Háplico & 841 & 2,6 \\
\hline $\begin{array}{l}\text { Gleissolo Melânico Tb Distrófico típico + Organossolo Háplico + Neossolo Quartzarênico Hidromórfico } \\
\text { Distrófico }\end{array}$ & 741,3 & 2,29 \\
\hline Latossolo Amarelo Distrófico psamítico + Latossolo Vermelho-Amarelo distrófico típico & 5241,4 & 16,2 \\
\hline Latossolo Amarelo Distrófico psamítico + Neossolo Quartzarênico Órtico latossólico & 2214,4 & 6,84 \\
\hline Latossolo Vermelho-Amarelo Distrófico cambissólico & 49 & 0,15 \\
\hline Latossolo Vermelho-Amarelo Distrófico típico & 1022,9 & 3,16 \\
\hline Latossolo Vermelho-Amarelo Distrófico típico + Argissolo Vermelho-Amarelo Distrófico arênico & 940,8 & 2,9 \\
\hline Latossolo Vermelho-Amarelo Distrófico típico + Cambissolo Háplico Tb Distrófico petroplíntico & 441,9 & 1,36 \\
\hline Latossolo Vermelho-Amarelo distrófico típico + Latossolo Amarelo Distrófico psamítico & 11485 & 35,5 \\
\hline Latossolo Vermelho Distrófico típico & 434,6 & 1,34 \\
\hline Neossolo Quartzarênico Hidromórfico + Gleissolo Háplico + Organossolo Háplico & 437,4 & 1,35 \\
\hline Neossolo Quartzarênico Hidromórfico típico & 9,1 & 0,03 \\
\hline Neossolo Quartzarênico Órtico típico & 1965,5 & 6,07 \\
\hline Organossolo Háplico + Gleissolo Melânico Tb Distrófico típico & 29,7 & 0,09 \\
\hline
\end{tabular}

hidromórficos, com alto índice de saturação hídrica durante a maior parte do ano, principalmente Organossolos, ocorrendo associadas à Mata de galeria e campos limpos úmidos ao longo dos corpos d'água e cabeceiras de drenagem, exercendo papel fundamental na distribuição dos rios e seus afluentes e na manutenção da fauna do cerrado.

O terraço fluvial do rio Formoso possui uma sequência de solos que obedece a uma sutil variação no gradiente do relevo em direção a sua calha. Nas faixas mais extensas desse terraço é possível encontrar uma associação contendo três classes de solos, partindo dos Neossolos Quartzarênicos Hidromórficos na sua borda, cobertos com cerrado sentido restrito ralo e campo limpo; seguido por Gleissolo Melânico sob campo limpo úmido na faixa intermediária e finalizando com os Organossolos Háplicos, onde a vegetação é muito semelhante à encontrada nas Veredas. É comum a presença de Campo limpo úmido circundando Veredas e Mata de galeria ocupados principalmente pela gramínea denominada capim-agreste (Trachypogon macroglossus Trin.) (Figura 4). Nas áreas mais estreitas de terraço, a sequência é diretamente dos Gleissolos Melânicos para Organossolos Háplicos. Essas áreas estão sujeitas a inundações periódicas.

Considerando os valores médios dos elementos encontrados nas análises físicas e químicas, das amostras de solos coletadas sob as diferentes fitofisionomias, observaram-se baixos teores de $\mathrm{Al}^{+3} \mathrm{~s}$ em todas as coberturas. Porém, entre esses, os ambientes hidromórficos (Campo limpo, Campo limpo úmido e Veredas) apresentaram os teores mais elevados (Figura 5A), o que está relacionado à condição redutora desses ambientes, que permite o maior acúmulo de matéria orgânica 


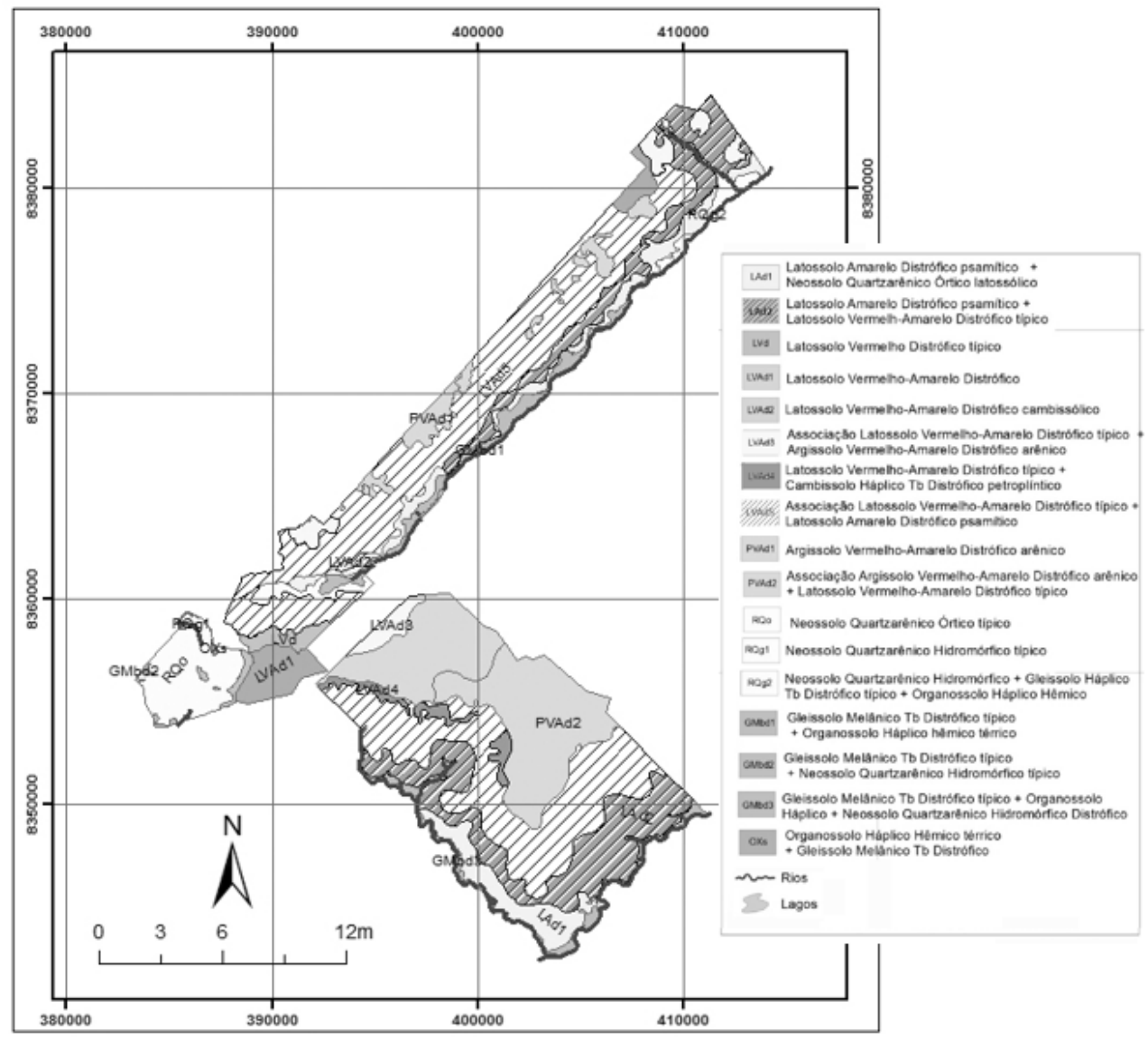

FIGURA 3: Unidades de solos mapeados na área de estudo.

FIGURE 3: Soil units mapped in the study area.

e, conforme observado por Vance et al. (1996), a fração orgânica do solo possui a capacidade de complexar cátions, entre eles $\mathrm{o} \mathrm{Al}^{+3}$. Essa relação pode ser verificada na Figura 5B, na qual os maiores valores correspondem às fisionomias em solos com teores de $\mathrm{Al}^{3+}$ mais elevados.

As áreas de Cerrado sentido restrito denso (CRD) apresentaram teor elevado de Corg, devido à maior cobertura florestal dessa fisionomia e consequentemente maior aporte de serrapilheira. Alcântara Neto et al. (2011), também encontraram resultado semelhante, no qual o CRD apresentou teores mais elevados de Corg quando comparado a outras formações de Cerrado sentido restrito. Com esse resultado pode-se supor que a ciclagem de nutrientes é mais efetiva no ambiente de Cerradão distrófico, quando comparado com o CRD, pois, apesar da sua maior capacidade de produção de biomassa, apresentou baixo teor de Corg no solo. Isso pode estar relacionado a uma menor atividade da microbiota nos Latossolos sob CRD devido à baixa disponibilidade de nutrientes encontrados nesses solos, o que permite um maior acúmulo da matéria orgânica nesse sistema, conforme verificado por Graham et al. (2002) e Silva et al. (2010).

$\mathrm{Na}$ Figura 5C pode-se verificar que capacidade de troca catiônica do solo (CTC - valor T) também está diretamente relacionada com o teor de Corg, em que os valores mais elevados foram encontrados nas áreas hidromórficas, indicando baixa contribuição da fração mineral (argila) na CTC. Resultados semelhantes foram encontrados por Magnago et al. (2010) estudando relação de fitofisionomias da restinga com solos arenosos desse ambiente. Ou seja, a capacidade de acúmulo de matéria orgânica, que está relacionada em parte com o nível de encharcamento/drenagem do solo, é um dos principais processos de diferenciação entre os ambientes estudados, que juntamente com a textura, influenciam diretamente o padrão de cobertura vegetal presente na área. Em relação ao fósforo, verificaram-se valores baixos em todas as 

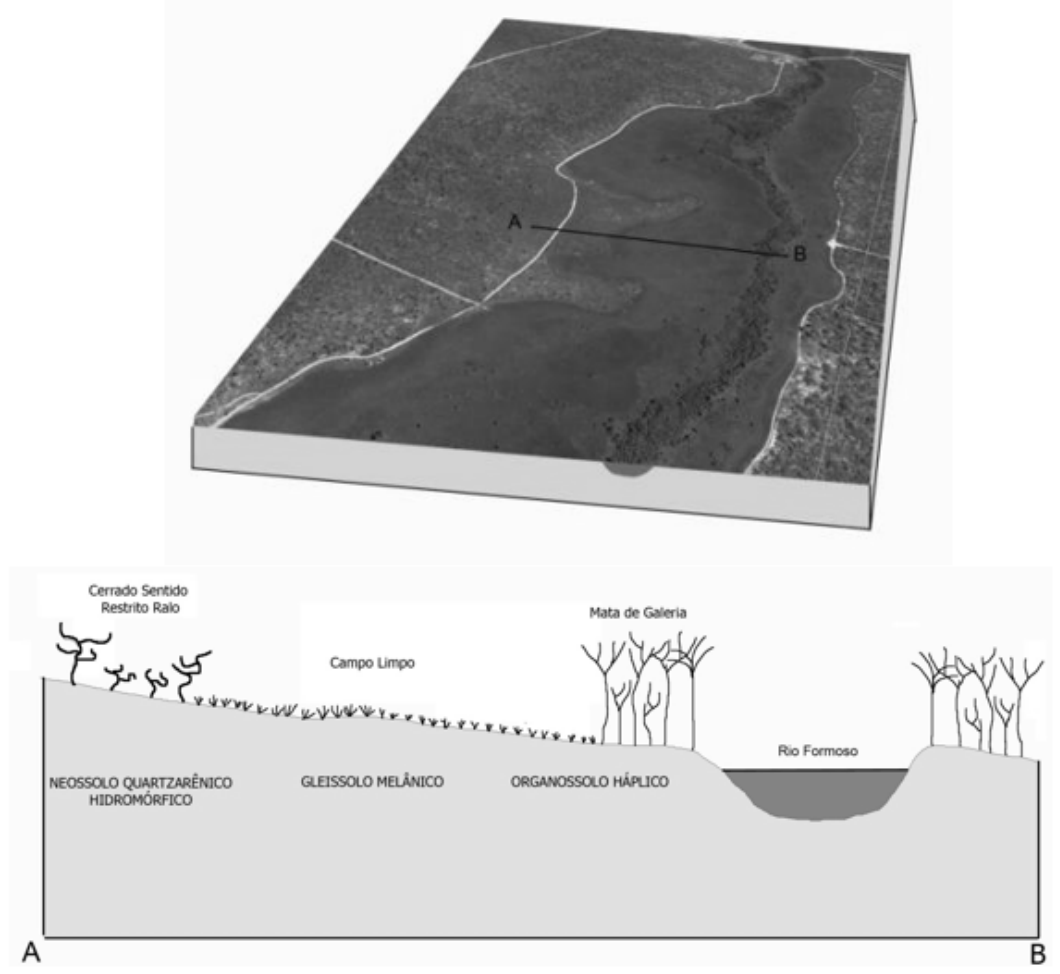

FIGURA 4: Terraço do rio Formoso e esquema da distribuição dos solos e fitofisionomias.

FIGURE 4: Formoso river terrace and layout of the distribution of soil and phyto-physiognomy.

fitofisionomias. (Figura 5D).

Na Figura 5E observa-se que os solos mais argilosos encontram-se sob Cerradão e Cerrado sentido restrito denso, o que pode indicar que os solos com texturas mais argilosas permite a formação de condições favoráveis para que as fisionomias florestais se desenvolvam, principalmente em função da possibilidade de estar ocorrendo maior retenção da umidade nesses ambientes. A melhor compreensão desses mecanismos de interações pode favorecer processos de recuperação futura de áreas de Cerrado. Já a presença de solos mais arenosos confere maior permeabilidade e, consequentemente, perda de umidade e nutrientes por lixiviação mais acentuada (BRITEZ 2005), enquanto que nos solos mais argilosos esse processo não é tão intenso, promovendo maior retenção de nutrientes nestas áreas. Condições similares foram reportadas por Guedes et al. (2006), Carvalho et al. (2005) e Magnago et al. (2010). A exceção ocorre nos solos arenosos dos terraços fluviais em função da superficialidade do lençol freático.

Analisando a Figura 5F verifica-se uma distinção dos teores de silte para os solos sob Campo limpo úmido e Cerrado sentido restrito ralo. Trata-se de áreas localizadas principalmente no terço inferior da paisagem, às margens dos fundos dos vales, que se constituem ambiente deposicional. Essa situação pode ocasionar uma provável contribuição de materiais de silte transportados de posições mais elevadas, uma vez que, são formados em terrenos de recepção ou trânsito de produtos transportados.

Aanálise dos componentes principais buscou através do diagnóstico conjunto de combinações lineares de 17 variáveis, determinar quais respondem pela maior parte da variabilidade dos dados. Nesse caso, três componentes apresentaram valores maiores que 1 (areia fina, argila, alumínio) que juntos responderam por $93,7 \%$ da variabilidade dos dados originais (Tabela 3 ), ou seja, basicamente a textura do solo e os teores de $\mathrm{Al}^{+3}$, sendo que esse último está diretamente relacionado com o teor de carbono orgânico do solo.

Considerando apenas os eixos dos componentes de maior influência, a Figura 6 confirma o fato de o teor de argila estar diretamente relacionado com a distribuição do Cerradão e do Cerrado sentido restrito típico, esse último 


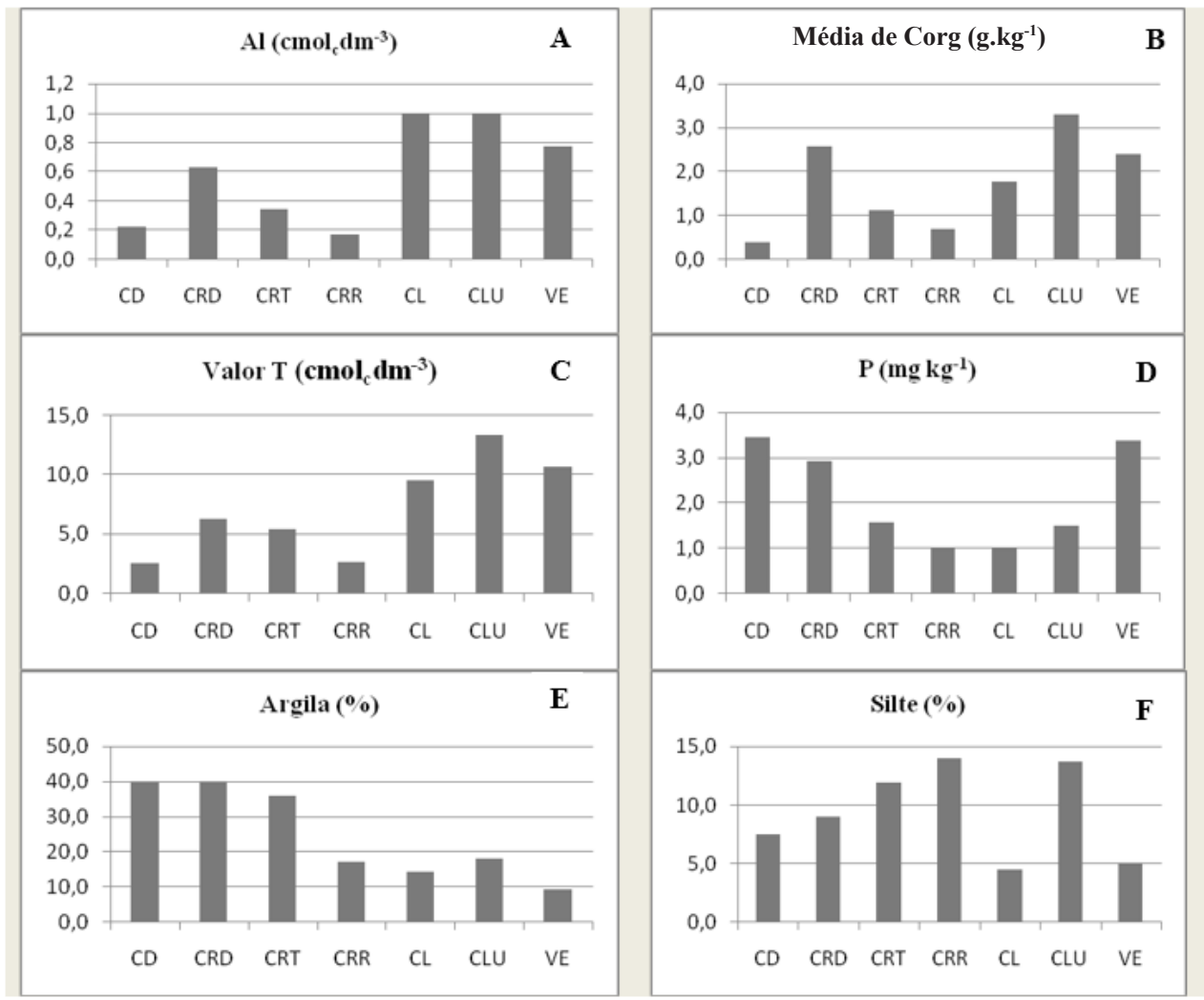

FIGURA 5: Média dos diferentes elementos encontrados e analisados nos solos de cada fitofisionomia presente na área de estudo. $\mathrm{CL}=$ Campo limpo; $\mathrm{CD}=$ Cerradão Distrófico; $\mathrm{CRD}=$ Cerrado sentido restrito denso; $\mathrm{CRT}=$ Cerrado sentido restrito típico; $\mathrm{VE}=$ Vereda; $\mathrm{CLU}=\mathrm{Campo}$ limpo úmido; $\mathrm{CRR}=$ Cerrado sentido restrito ralo.

FIGURE 5: Average of different elements found in soils and analyzed for each phyto-physiognomy present in the study area. $\mathrm{CL}=$ Campo Limpo; $\mathrm{CD}=$ Cerradão Dystrophic; $\mathrm{CRD}=$ dense Cerrado; $\mathrm{CRT}=$ typical Cerrado; $\mathrm{VE}=$ Vereda; $\mathrm{CLU}=$ Wet Campo Limpo; $\mathrm{CRR}=$ drain Cerrado.

TABELA 3: Resultado da análise dos componentes principais em relação aos atributos dos solos. TABLE 3: Results of principal component analysis in relation to soil attribute.

\begin{tabular}{clcc}
\hline Componente & \multicolumn{1}{c}{ Autovalor } & Variância $(\%)$ & Percentagem acumulada \\
\hline Areia fina & 8.946 & 52.623 & 52.623 \\
Argila & 5.269 & 30.994 & 83.617 \\
Alumínio & 1.713 & 10.077 & 93.694 \\
Argila natural & 0.5826 & 3.427 & 97.121 \\
Argila total & 0.4894 & 2.879 & 100.000 \\
Areia total & $8.235 \mathrm{E}-16$ & 0.000 & 100.000 \\
$\mathrm{Ca}^{2+}$ & $6.197 \mathrm{E}-16$ & 0.000 & 100.000 \\
$\mathrm{Corg}^{+}$ & $4.02 \mathrm{E}-16$ & 0.000 & 100.000 \\
$\mathrm{H}^{+}$ & $2.909 \mathrm{E}-16$ & 0.000 & 100.000 \\
$\mathrm{~K}^{+}$ & $2.33 \mathrm{E}-16$ & 0.000 & 100.000 \\
$\mathrm{Mg}^{++}$ & $8.281 \mathrm{E}-17$ & 0.000 & 100.000 \\
$\mathrm{P}$ & $2.456 \mathrm{E}-17$ & 0.000 & 100.000 \\
$\mathrm{pH}, \mathrm{S}$, Silte, CTC, $\mathrm{V}$ & 0.0 & 0.000 & 100.000 \\
\hline
\end{tabular}

Em que: Corg = carbono orgânico; $\mathrm{S}=$ Somo de bases; $\mathrm{V}=$ saturação por bases. 


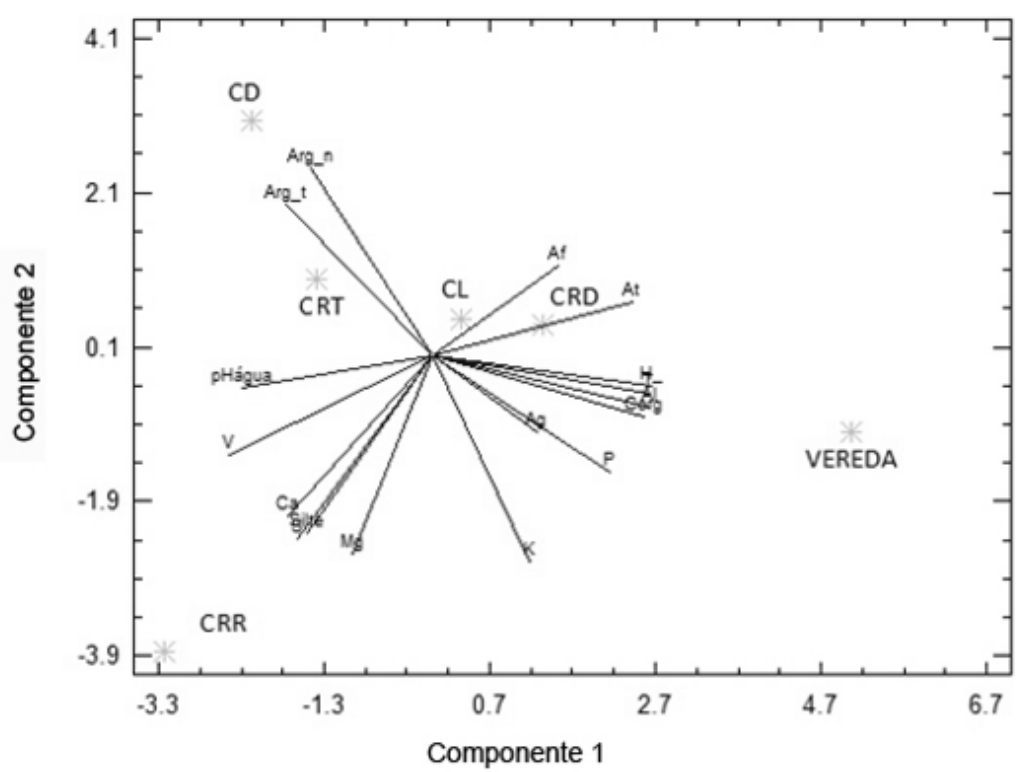

FIGURA 6: Análise canônica da relação dos atributos dos solos e as fitofisionomias. $\mathrm{CL}=\mathrm{Campo}$ limpo; $\mathrm{CD}=$ Cerradão Distrófico; $\mathrm{CRD}=$ Cerrado sentido restrito denso; $\mathrm{CRT}=$ Cerrado sentido restrito típico; $\mathrm{CRR}=$ Cerrado sentido restrito ralo; $\operatorname{Arg} \_\mathrm{n}=\operatorname{argila}$ natural; $\operatorname{Arg} \_\mathrm{t}=\operatorname{argila}$ total; $\mathrm{V}$ = saturação por bases; Corg = carbono orgânico; $\mathrm{Af}=$ areia fina; $\mathrm{Ag}=$ areia grossa; At $=$ areia total.

FIGURE 6: Canonical analysis of the attributes soil and phyto-physiognomy relation. $\mathrm{CL}=\mathrm{Campo}$ Limpo; $\mathrm{CD}=$ Dystrophic Cerradão; $\mathrm{CRD}=$ dense Cerrado; $\mathrm{CRT}=$ typical Cerrado; $\mathrm{CRR}=$ drain Cerrado; $\arg \_\mathrm{n}=$ natural clay; $\operatorname{Arg} \_\mathrm{t}=$ total clay; $\mathrm{V}=$ saturation bases; $\mathrm{Corg}=$ organic carbon; $\mathrm{Af}=$ fine sand; $\mathrm{Ag}=$ coarse sand; $\mathrm{At}=$ total sand.

representando a fitofisionomia mais frequente na área estudada. Já os teores de areia fina e areia total influenciam na presença do Cerrado sentido restrito denso e do Campo limpo, enquanto os teores de $\mathrm{Al}^{+3}$ tendem a estar mais relacionados à presença das Veredas, juntamente com o carbono orgânico e o $\mathrm{H}^{+}$, em função das características desse ambiente.

\section{CONCLUSÕES}

O Cerrado sentido restrito típico é a fitofisionomia mais abundante na área de estudo, ocupando $67 \%$ do total. A Ordem de solo mais comum foi a do Latossolo, sendo a associação entre Latossolo Vermelho-Amarelo e Latossolo Amarelo a unidade de mapeamento mais representativa, presente em mais de $35 \%$ de toda a área.

O teor de matéria orgânica, que está relacionada com o nível de encharcamento/ drenagem do solo, é um dos principais fatores de diferenciação entre os ambientes estudados, que, juntamente com a textura, influenciaram diretamente nas características dos solos e determinaram a distribuição das diferentes fitofisionomias na área de estudo.

A análise dos componentes principais indicou que a areia fina, a argila e o alumínio responderam por $93,7 \%$ da variabilidade das fitofisionomia em relação aos solos.

\section{AGRADECIMENTOS}

A Universidade Federal Rural do Rio de Janeiro, a CAPES e Fazendas Trijunção por todo o apoio ao desenvolvimento deste trabalho.

\section{REFERÊNCIAS BIBLIOGRÁFICAS}

AGNES, C. C. et al. Fatores ecológicos condicionantes da vegetação do Cerradão. Caderno de Pesquisa Sér. Bio., Santa Cruz do Sul, v. 19, n. 3, p. 25-37, 2007.

ALCÂNTARA NETO, F. et al. Compartimentos de carbono em Latossolo Vermelho sob cultivo de 
eucalipto e fitofisionomias de cerrado. Rev. Bras. Ciênc. Solo, Viçosa, v. 35, n. 3, jun. 2011.

BAHIA. SEI. Superintendência de Estudos Econômicos e Sociais da Bahia. Análise dos atributos climáticos do Estado da Bahia. Salvador, 1998. 85 p. (Serie Estudos e Pesquisas, 38).

BRITEZ, R. M. Solos. In: MARQUES, M. C. M.; BRITEZ, R. M (orgs.). História natural e conservação da Ilha do Mel, Paraná. Curitiba: Ed. da UFPR, 2005. P. 49-84.

CARVALHO, D. A. et al. Distribuição de espécies arbóreo-arbustivas ao longo de um gradiente de solos e topografia em um trecho de floresta riparia do Rio São Francisco em Três Marias, MG, Brasil. Revista Brasileira de Botânica, v. 28, n. 2, p. 329-345. 2005.

CASTRO, E. A.; KAUFFMAN, J. B. Ecosystem structure in the Brazilian Cerrado: a vegetation gradient of aboveground biomass, root biomass and consumption by fire. Journal of Tropical Ecology, v. 14, p. 263-283, 1998.

CREMON, C. et al. Atributos do solo em diferentes fitofisionomias do Cerrado Mato-grossense. Agrarian, v. 2, n. 6, p.53-59, 2009

CRUZ, C. D.; REGAZZI, A. J. Modelos biométricos aplicados ao melhoramento genético. Viçosa: Ed.Universidade Federal de Viçosa, 1994. 394 p. EMBRAPA. Manual de métodos de análises de solo. 2. ed. Rio de Janeiro: Centro Nacional de Pesquisa de Solos, 1997. 212 p.

EMBRAPA. Sistema Brasileiro de Classificação de Solos. Rio de Janeiro: Centro Nacional de Pesquisa de Solos, 2006. 306 p.

GRAHAM, M. H.; HAYNES, R. J.; MEYER, J. H. Soil organic matter content and quality: effects of fertilizer applications, burning and trash retention on a long-term sugarcane experiment in South Africa. Soil Biol. Biochem., v. 34, p. 93-102, 2002.

GUEDES, D.; BARBOSA, L. M.; MARTINS, S. E. Composição florística e estrutura fitossociológica de dois fragmentos de floresta de Restinga no Município de Bertioga, SP, Brasil. Acta Botânica Brasilica, v. 20, n. 2, p. 299-311, 2006.

KOTCHETKOFF-HENRIQUES, O.; JOLY, C. A.; BERNACCI, L. C. Relação entre o Solo e a Composição Florística de Remanescentes de Vegetação Natural no Município de Ribeirão Preto, SP. Revista Brasil. Bot., v. 28, n. 3, p. 541-562, jul.-set. 2005.

LIMA, O. A. L. Levantamentos geofísicos no
Aqüífero Urucuia: sub-bacias dos rios Arrojado e Formoso, rede cooperativa: comportamento de bacia Sedimentares na região semi-árida do nordeste Brasileiro. Relatório. Salvador: Universidade Federal da Bahia, Centro de Pesquisa em Geofísica e Geologia, 2007. 37 p.

LOSS, A. et al. Agregação, carbono e nitrogênio em agregados do solo sob plantio direto com integração lavoura-pecuária. Pesq. Agropec. Bras. v. 46, n. 10, p. 1269-1276, 2011.

MAGNAGO,L.F. S. etal. Gradiente fitofisionômicoedáfico em formações florestais de Restinga no Sudeste do Brasil. Rev. Acta Bot. Bras. v. 24. n. 03, p. 734-746, 2010.

MARIMON JUNIOR, B. H.; HARIDASAN, M. Comparação da vegetação arbórea e características edáficas de um Cerradão e um Cerrado sensu stricto em áreas adjacentes sobre solo distrófico no leste de Mato Grosso, Brasil. Acta Bot. Bras. v.19 n. 4, p. 45-52, Oct./Dec, 2005.

MEDEIROS, D. A. Métodos de amostragens no levantamento da diversidade arbórea do Cerradão da Estação Ecológica de Assis. 2004. 213 f. Dissertação (Mestrado em Agronomia) Escola Superior de Agricultura Luiz de Queiros, Piracicaba, 2004.

RIBEIRO, J. F. e WALTER, B. M. T. As principais fitofisionomias do bioma Cerrado in: SANO, S. M.; DE ALMEIDA, S. P., RIBEIRO, J. F. Cerrado Ecologia e Flora. Brasília: Embrapa Informação Tecnológica, 2008, 406 p.

ROSSI, M. et al. Relação Solos/vegetação em Área Natural no Parque Estadual de Porto Ferreira, São Paulo: Rev. Inst. Flor., v. 17, n. 1, p. 45-61, jun. 2005.

SANTOS, R. D. et al. Manual de descrição e coleta de solo no campo. 5. ed. Viçosa: Ed. Universidade Federal de Viçosa, 2005. 91 p.

SILVA, R. R. et al. Biomassa e atividade microbiana em solo sob diferentes sistemas de manejo na região fisiográfica Campos das Vertentes - MG. R. Bras. Ci. Solo, v. 34, p. 1585-1592, 2010.

SOUZA, V. C.; LORENZI, H. Botânica Sistemática - Guia ilustrado para identificação das famílias de angiospermas da flora brasileira, baseado em APG II. Nova Odessa: Plantarum, 2005. 167 p. VANCE, G. F.; STEVENSON, F. J.; SIKORA, F. J. Environmental chemistry of aluminumorganic complexes. In: SPOSITO, G. (Ed.). The enviromental chemistry of aluminum. $2^{\text {nd }}$ ed. Flórida: Lewis Publishers, 1996. p.169-220. 